Postprint.

For published article see:

Yao, R., \& Meng, X. (2018). Credit card usage among college students in China. Journal of Financial Counseling and

Planning, 29(2), 304-315. http://dx.doi.org/10.1891/1052-3073.29.2.304

\title{
Credit Card Usage Among College Students in China
}

\begin{abstract}
Credit cards have become a common method of payment for college students in China. It is important that they form good credit card usage behaviors and build a good credit history early in their financial life. Using data collected from 10 universities in China, results of this study found that being financially dependent on their parents is negatively associated with Chinese college students' ability to pay their credit card bills. The study also found that students with a high level of financial knowledge were less likely to take cash advances on their credit card. Implications for financial educators and parents as well as policymakers were provided.
\end{abstract}

Keywords: cash advance, China, college students, credit card

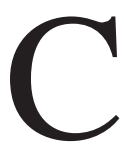

redit cards are a common method of payment for most college students. Although they provide access to funds when other methods of payment

are limited, using such funds can accumulate high costs. Credit card companies believe that college students have the potential to earn higher incomes in the near future and therefore issue cards to young consumers even if they do not currently have a credit history or a steady income (Robb, 2011). This relationship that creates the initial exposure to the consumer credit market may help increase their loyalty as well. According to a survey conducted by a US student loan provider, Sallie Mae (2013), credit card usage among US college students has remained at approximately $30 \%$ since 2010 . In 2016, more than half (56\%) of college students between the ages of 18 and 24 years held a credit card (Sallie Mae, 2016). These credit card users are typically financially dependent but also have a strong tendency to buy new products and make their own decisions.

Using credit cards can provide enormous benefits, such as convenience, expense budgeting, and the accumulation of a credit history; however, it also comes with responsibilities, such as paying bills on time, staying under the credit limits, and understanding the terms and conditions of the card. Based on a multicampus survey, college students lacked knowledge of interest rates and late payment charges for their credit cards (Ludlum et al., 2012). Unlike other age groups, college students are being exposed to the consumer credit market for the first time in their lives and must deal with the issues associated with real-world debts (Xiao, Ahn, Serido, \& Shim, 2014). Questions have been raised about college students' ability to use credit cards responsibly as well as their attitudes about money and consumption. In order to help college students de- velop good spending habits, it is important for educators and policymakers to investigate the ways in which these students use credit cards.

Researchers have studied American college students' credit cards usage for decades, but few studies have been conducted among other cultures. Being the second largest economy in the world, China has huge market potential for credit cards, and the number of credit card owners in China has grown significantly over the past several years. According to China Real News (2014, 2015), Chinese banks had issued 414 million credit cards as of the first quarter of 2014, an increase of 5.8\% since the end of 2013; and a total of 511 million credit cards in the first half of 2015, an $8.9 \%$ increase since the end of 2014 . Worthington, Thompson, and Stewart (2011) indicated that China is very savings- and cash-centric, rather than borrowing- and credit card-centric. However, they indicated that young and affluent Chinese credit card users 
exhibit the traits of those who acquire new products and indicate that credit cards offer them greater convenience.

In 2004, a Chinese bank issued the first credit cards to college students (Li, Wang, \& Xu, 2014). According to these authors, the Jin Cheng International Credit Management Co., Ltd., along with the Guangdong Development Bank, issued the first domestic credit cards to college students in Beijing. This showcased the enormous opportunity available to other commercial banks to enter the student credit card market. Sure enough, an increasing number of banks began to issue various credit cards with the use of campus promotions. The dramatic increase in credit card usage among Chinese college students has generated concern about whether they are using credit cards in appropriate ways or are engaging in risky behaviors. An example of harmful behavior would be not paying the credit card balance in full or taking cash advances (Xiao et al., 2014). In order to protect credit card users and to prevent young generations from getting into debt, in 2011, the China Banking Regulatory Commission issued provisions to improve and standardize credit card market. Banks are prohibited from issuing credit cards to people who are aged under 18 years old (excluding supplementary card applicants). In addition, people over the age of 18 years who do not have a stable income will need a co-signer to ensure that there is a secondary source of repayment (Measures for the Supervision and Administration of the Credit Card Business of Commercial Banks, 2011).

Most people in China do not like to carry debt. Traditionally, they control their consumption and maintain conservative cash spending habits (Li et al., 2014). However, Chinese college students are well aware of the Chinese saving tradition and therefore are likely influenced by Western consumerism. They are a unique group of people who may accept new spending and borrowing concepts in addition to the usage of credit cards. Currently, not much is known about college students' usage of credit cards because data on their financial behavior in China are limited. To fill in this gap, this study used data collected by 10 universities in Beijing and Tianjin in 2014 to explore the factors related to college students' credit card usage - specifically, their payment and cash advance behaviors. The findings tracked Chinese college students' credit card usage and provided insights on how to help them avoid making mistakes when using credit cards as well as on the importance of financial education.

\section{Literature Review and Hypotheses Credit Cards in China}

In 1985, the Bank of China (BOC) produced the first domestic Chinese credit card, the Great Wall Card (Worthington, 2003). In 1987, the BOC joined the international credit card associations, MasterCard, and Visa and issued its first international Great Wall MasterCard in 1988. According to Worthington (2003), by the end of 1997, over 30 million Chinese held a Great Wall Card. The other three banks out of the "big four" Chinese banks followed the BOC's lead and began to issue credit cards to Chinese consumers. Between 1990 and 2001, the number of cards held by Chinese people increased from 3 to 330 million (Worthington, 2003). In 2007, China experienced another boom in credit card acquisition. According to data provided by Statista (2016), the number of credit cards acquired in China in 2007 had increased by $80 \%$ compared to that of 2006 . After 2009 , annual growth in the total number of credit cards held declined to $36 \%$, and from 2010 to 2014 , the annual growth rate hovered at approximately $16 \%-20 \%$. China, a traditional cash-centric society, has experienced a rapid growth of credit card ownership.

\section{Characteristics of Chinese Credit Card Users}

Most existing research on credit card usage in China has been conducted from the perspective of general consumers. Worthington, Stewart, and Lu (2007) examined 196 respondents with an average annual income of 200,000 RMB (approximately US $\$ 26,385$ in 2007). Approximately $67.9 \%$ of respondents used a credit card regularly, and either paid off their debts each month $(84.5 \%)$ or only made the minimum or partial payments of their balances $(15.5 \%)$. This suggested that the sample of Chinese consumers were using credit cards appropriately. Respondents who paid their balances in full appeared to be well aware of the risks and advantages of using credit cards compared to those who did not pay their balances in full. The authors predicted that credit card products would continue to influence the choice of payment options in the Chinese market.

Wang, Lu, and Malhotra (2011) used a 2008 sample of 1,410 credit card holders in China and noted credit card users with revolving debt (individuals who pay between the minimum payment and the full payment) are typically younger than 37 years old. Males were less likely than females to pay the full monthly balances, while individuals with higher incomes were less likely to carry balances. Student card holders held 
revolving debt significantly more often than working professionals. Finally, they found that self-control, self-esteem, and self-efficacy were related negatively to the frequency of holding revolving debt. People who scored high on one or some of these variables were able to manage their financial accounts by avoiding carrying excessive debt.

A study by Sharpe, Yao, and Liao (2012) used a sample of 2,071 Chinese urban households and found that the credit card ownership of Chinese individuals was related to age, education, and income level. Approximately $60 \%$ of credit card owners were younger than 35 years and were more aware of the general risks associated with using credit cards. Their findings suggested that younger affluent individuals are more likely to utilize credit cards as a new payment method.

There has been limited research conducted on credit card use from the perspective of college students. Most Chinese college students receive financial support from their parents and thus have a greater temptation to spend. Although they have no stable source of income, their level of consumption is high. For example, the per capita annual expenditure of urban residents in 2015 was approximately 21,392 yuan (approximately US $\$ 3,396$ in 2015), while over half of Chinese college students spend 1,000-3,000 yuan monthly (approximately US \$159-\$476 in 2015), and about onethird of them spend 3,0005,000 yuan monthly (approximately US $\$ 476$ to $\$ 781$ in 2015) (People.cn, 2016). To identify respondents who fit the profile of "young affluent Chinese," Worthington et al. (2011) employed a survey to evaluate students on the Ningbo campus at the University of Nottingham. They noted that the responding undergraduate students had a median annual income of 20,000 RMB (approximately US $\$ 3,096$ in 2011), which indicated that they received allowances from their parents. The majority of undergraduate students in the sample had a credit card, and nearly three-quarters used credit cards several times a month. These students stated that the convenience that credit cards provide was the most important reason for their usage. The students in the sample reported that they used credit cards for shopping instead of cash withdrawals. They were aware of the high costs of taking cash advances on credit cards and also had concerns that using credit cards encourages people to spend beyond their budgets; however, they believed that by exercising self-control, they could effectively control their spending habits.
By analyzing a sample of college students in the United States and China, Norvilitis and Mao (2013) found that Chinese students were less confident in their ability to manage money and credit. Thus, self-reported financial confidence and wealth satisfaction levels should be considered when examining Chinese students' credit card usage. Within the context of Chinese culture, children are not considered independent until they graduate from college and join the labor force. The majority of Chinese college students receive financial support from their families because their incomes from part-time jobs or scholarships usually do not cover their college expenses. Norvilitis and Mao (2013) concluded that $11 \%$ of Chinese parents have paid the credit card debts of their children who are in their 20s. Parental involvement is another influence on credit card use for Chinese college students.

\section{Characteristics of American Students' Paying Behavior}

Data on college students' financial behavior in China is limited. College students in the United States have a longer history of credit card usage than Chinese students (Norvilitis $\&$ Mao, 2013). The behavior of US students may provide insights into how Chinese students behave because they are likely to adopt Western spending and borrowing concepts.

Based on the existing research, most US college students with positive credit card balances pay their credit bills in full each month (Joo, Grable, \& Bagwell, 2003; Staten \& Barron, 2002; Tan, 2003; Robb \& Sharpe, 2009). Their year in college was related to their debt payment behavior. Freshmen and sophomores were more likely to pay their balances in full each month, while students with less educated parents were more likely to carry a revolving balance (Robb \& Sharpe, 2009). Xiao, Tang, Serido, and Shim (2011) found similar results indicating that parental socioeconomic status, such as income and education, had a negative effect on students' revolving credit card debt. They also found that students who had a higher level of self-efficacy were more likely to perform positive financial behaviors. Students who felt more confident about controlling their finances were more likely to perform positive financial behavior as well. Furthermore, Lyons (2004) pointed out that whether or not the student was financially independent played a key role in whether she/he engaged in risky financial behavior. Being financially independent decreased the likelihood of paying credit card balances in full each month. Other studies have confirmed that financial independence from parents was 
positively related to having high credit card debt and not paying balances in full each month (Mendes-Da-Silva, Nakamura, \& Moraes, 2012). In addition, Tan (2003) found that female students were more likely to have problems repaying debt. This is consistent with findings from Jassim and Taylor (2010) that state that a higher percentage of male students paid off their credit card balances in full every month when compared to female students.

\section{Role of Financial Knowledge}

Several studies have examined the relationship between financial knowledge and the credit card usage of college students. Although these studies analyzed college students in countries outside of China, results may provide insight into the analysis on Chinese college students. Robb (2011) found that a greater level of financial knowledge was associated with more responsible credit card usage for US college students. Students who received a higher score on financial literacy questions were less likely to make only the minimum payment and less likely to take cash advances. A recent study in Turkey found that students with higher financial literacy scores were more likely to pay their bills on time (Akben-Selcuk, 2015). Xiao et al. (2014) found that both objective (content knowledge demonstrated by test scores) and subjective (self-assessed understanding of content knowledge) knowledge decreased US college students' undesirable credit paying behaviors. Some examples of these behaviors are not paying balances in full and borrowing behaviors, such as taking cash advances on credit cards.

A study by Norvilitis and MacLean (2010) examined the impact parents have on college student credit card usage. The sample of 173 college students were asked where they learned the most about managing their finances. The results showed that most students learned about money from their parents. Other financial knowledge resources included school, friends, the media, and their own experiences. They indicated that there was no difference in credit card debt regardless of which resource they received knowledge from. Their findings complemented those of Bowen's (2002), who found that the level of financial knowledge of teens and their parents was unrelated. In contrast, Pinto, Parente, and Mansfield (2005) pointed out that college students received more credit card knowledge from their parents than any other resources. Students who learned more information about credit cards from their parents were less likely to carry outstanding balances. There was no significant relationship between other resources and credit card usage.

Considering the importance of financial independence and financial knowledge in forming good financial behaviors and based on results from prior literature, we hypothesize that:

$\mathrm{H} 1$ : The likelihood of engaging in undesirable financial behaviors is lower for Chinese college students who are fully financially dependent on their parents.

$\mathrm{H} 2$ : The likelihood of engaging in undesirable financial behaviors is lower for Chinese college students who have a higher level of financial knowledge.

\section{Methodology \\ Data}

In this study, we used data collected by the Central University of Finance and Economics to explore the factors related to college students' credit card usage. Data were collected in 2014 via the Internet and WeChat before and after participation in the "College Students Financial Literacy Education Program," a 1-year program cosponsored by the China Foundation for Poverty Alleviation and Citi Foundation. The program is designed to effectively enhance college students' financial knowledge and financial capacity as well as the responsibility they exercise when utilizing credit card. The course contents covered topics such as the use of banks, establishing financial goals, and the basics of credit, savings, and investments.

Respondents were students from 10 universities in Beijing and Tianjin, China. Student organizations helped promote the educational program. Survey participation was voluntary. Volunteers were randomly selected to participate in the program. An initial survey was conducted to collect information on the demographic and economic characteristics of the program participants and their parents, in addition to information about the respondents' financial attitudes, life satisfaction, and self-reported financial knowledge. The total sample size of the initial survey was 1,359 .

To examine factors related to credit card usage, we eliminated respondents who reported that they did not have a credit card. The final sample size was 499 (49.1\% male, $50.9 \%$ female). Table 1 shows the characteristic of the 


\begin{tabular}{|c|c|c|c|c|c|c|}
\hline \multirow[b]{2}{*}{ Characteristics } & \multicolumn{3}{|c|}{ Credit Card Paying Behavior } & \multicolumn{2}{|c|}{$\begin{array}{c}\text { Take Cash Advances on } \\
\text { Credit Card }\end{array}$} & \multirow[b]{2}{*}{ Total } \\
\hline & mum and Full & Pay in Full & Parents Pay & No & Yes & \\
\hline \multicolumn{7}{|l|}{ Gender } \\
\hline Male & 14.8 & 26.5 & 7.8 & 14.6 & 34.5 & 49.1 \\
\hline Female & 11.2 & 27.7 & 12.0 & 15.6 & 35.3 & 50.9 \\
\hline \multicolumn{7}{|l|}{ Year in school } \\
\hline Freshman & 17.4 & 36.3 & 14.8 & 17.2 & 51.3 & 68.5 \\
\hline Sophomore or higher & 8.6 & 17.8 & 5.0 & 13.0 & 18.4 & 31.5 \\
\hline \multicolumn{7}{|l|}{ Parents' monthly income } \\
\hline 0-4,999 yuan & 15.8 & 30.5 & 8.4 & 14.2 & 40.5 & 54.7 \\
\hline 5,000 yuan or more & 10.2 & 23.6 & 11.4 & 16.0 & 29.3 & 45.3 \\
\hline \multicolumn{7}{|l|}{ Parents' highest education } \\
\hline High school or lower & 19.4 & 35.1 & 9.6 & 16.2 & 47.9 & 64.1 \\
\hline Associate degree or higher & 6.6 & 19.0 & 10.2 & 14.0 & 21.8 & 35.9 \\
\hline \multicolumn{7}{|l|}{ Last year total income } \\
\hline 0-4,999 yuan & 14.8 & 32.1 & 8.4 & 14.6 & 40.7 & 55.3 \\
\hline 5,000 yuan or more & 11.2 & 22.0 & 11.4 & 15.6 & 29.1 & 44.7 \\
\hline \multicolumn{7}{|c|}{ Full financial dependence on parents } \\
\hline Yes & 12.6 & 26.5 & 14.8 & 16.2 & 37.7 & 53.9 \\
\hline No & 13.4 & 27.7 & 5.0 & 14.0 & 32.1 & 46.1 \\
\hline \multicolumn{7}{|c|}{ Know credit card cash withdraw rate } \\
\hline Yes & 6.6 & 16.6 & 2.8 & 3.4 & 22.6 & 26.1 \\
\hline No & 19.4 & 37.5 & 17.0 & 26.9 & 47.1 & 73.9 \\
\hline \multicolumn{7}{|l|}{ Source of financial knowledge } \\
\hline Parents & 11.2 & 20.8 & 9.2 & 10.6 & 30.7 & 41.3 \\
\hline Internet & 8.4 & 19.0 & 7.0 & 11.6 & 22.8 & 34.5 \\
\hline Other sources & 6.4 & 14.2 & 3.6 & 8.0 & 16.2 & 24.2 \\
\hline \multicolumn{7}{|c|}{ Calculated level of financial knowledge } \\
\hline Low & 13.4 & 15.0 & 4.0 & 8.8 & 23.6 & 32.5 \\
\hline Medium & 8.6 & 30.3 & 11.6 & 14.0 & 36.5 & 50.5 \\
\hline High & 4.0 & 8.8 & 4.2 & 7.4 & 9.6 & 17.0 \\
\hline
\end{tabular}

Note. Numbers in percentages. Sample size $=499$.

sample of students. The respondents on average were 19 years of age (standard deviation $=1.6$ ), and the majority were freshmen (68.5\%). More than half of the students were unemployed (60.1\%) and completely financially dependent on their parents (53.9\%). The majority of the students who were employed worked less than $10 \mathrm{hr} /$ week. Nearly all the students lived in a dorm (97.4\%), and none of them was married. Among the students who had at least one credit card, $26.0 \%$ of them reported that they paid between the minimum and the full payment, and $69.7 \%$ of them reported that they took cash advances on their credit cards. The overwhelming majority of the students $(94.8 \%)$ reported that they had between one and three credit cards, while only $5.2 \%$ reported that they had four or more credit cards. Approximately $15.8 \%$ of the respondents used their credit cards several times a week; $39.9 \%$ used them several times monthly, and $31.9 \%$ reported that they rarely used credit cards. Furthermore, $9.8 \%$ of respondents used credit cards for financial emergencies, and only $2.6 \%$ of respondents used their credit cards every day. 


\section{Variables}

The dependent variables were made up of the answers from two questions about credit card usage and were as follows: (a) how do you pay your credit card bills? and (b) do you take cash advances against your credit? The first dependent variable was designated to determine whether or not respondents paid more than the minimum payment on their credit card debts each month. The survey asked the respondents how they paid their credit card debts. The four primary payment method responses were (a) paying the minimum payment; (b) paying the amount between the minimum payment and the full payment; (c) paying in full; and (d) my parents pay. These methods were mutually exclusive since respondents could choose only one answer. The first three responses involve students who receive allowances from their parents but manage credit card payments on their own. The "my parents pay" response refers to the situation where parents take responsibility for managing their children's credit card bills. When we looked at frequency tables formed for the first two options and also the categorical predictor variables, some of the cells included a small number of observations, or others had no observation. In order to avoid having categories with small numbers of cases, this study combined the first two options into one category and kept the other two categories separate. The second dependent variable focused on respondents who took cash advances on their credit cards $(1=$ yes; $0=$ no $)$.

Based on the literature review, we selected independent variables and organized them into four groups: (a) demographic characteristics that include gender, year in school, previous year's income, and financial dependence (whether completely dependent on their parents); (b) parental socioeconomic status, such as parents' income and highest level of education; (c) financial confidence and satisfaction; and (d) sources and level of financial knowledge.

To evaluate their financial confidence and satisfaction, students answered the following two questions on a scale of 0 10 (10 indicated strongly agree, and 0 indicated strongly disagree): (a) "Are you satisfied with your current financial situation?" and (b) "Do you have an adequate ability to manage personal finances?"

In order to determine the respondents' level of financial knowledge, the survey included 11 questions that covered topics related to banking, credit cards, investment options, and other factors. Possible scores ranged from 0 to 11, depending on the number of correct answers. The number of correct responses to the questions about financial knowledge was used to assess an individual's level of objective knowledge (Fernandes, Lynch, \& Netemeyer, 2014). Students who answered less than seven questions correctly were considered to have a low level of financial knowledge. Students who answered seven or eight questions correctly were categorized as having a medium level of financial knowledge, and those who answered nine or more questions correctly were considered to have a high level of financial knowledge. A total of 337 respondents answered at least seven questions correctly, indicating that half of the students possessed at least a medium level of financial knowledge. Additionally, 85 of the students demonstrated a high level of financial knowledge.

We omitted the variables from our model that contained too many missing values. For example, we excluded academic performance from the model, as only 166 out of 499 respondents provided their grade point averages. Information on living arrangement was also excluded because most students lived in dormitories. We also eliminated marital status from the model due to the fact that no respondents were married. Some variables contained categories with very few cases, so we combined some categories. For example, we pooled respondents who were sophomores, juniors, and seniors and categorized them as "sophomore or higher." In addition, we tried to control the frequency of credit card usage and included this variable as an independent variable in our regression models. However, this variable was insignificant and thus deleted from the model selection process. Although the usage frequency was diverse, it did not affect students' credit card usage behavior.

\section{Multivariate Analysis Methods}

We performed a multinomial logistic regression to examine factors related to the credit card payment behavior of college students. This analysis was used because the dependent variable, "how do you pay your credit card," is categorical and has no internal order. It was also used because there were more than two categories. We used a binary logistic regression to test the second model because the outcome observed had only two possible outcomes. We conducted Pearson's correlation tests across independent variables. The number of hours that students worked per week was highly correlated with financial independence. However, the interaction term was insignificant, as were the weekly work hours, and thus, both were excluded from the models. 
TAbLe 2. Multinomial Logistic Analysis of Credit Card Payment behaviors (Reference Category = Parents Pay)

\begin{tabular}{|c|c|c|c|c|c|c|}
\hline \multirow[b]{2}{*}{ Parameter } & \multicolumn{3}{|c|}{ Pay Between Minimum and Full } & \multicolumn{3}{|c|}{ Pay in Full } \\
\hline & Coefficient & $\begin{array}{l}\text { Standard } \\
\text { Error }\end{array}$ & $\begin{array}{l}\text { Odds } \\
\text { Ratio }\end{array}$ & Coefficient & $\begin{array}{l}\text { Standard } \\
\text { Error }\end{array}$ & $\begin{array}{l}\text { Odds } \\
\text { Ratio }\end{array}$ \\
\hline Intercept & 1.5054 & 0.5670 & & 1.1973 & 0.5174 & \\
\hline Male (reference category = female) & 0.3586 & 0.2975 & 1.4313 & 0.1200 & 0.2618 & 1.1275 \\
\hline \multicolumn{7}{|l|}{$\begin{array}{l}\text { Year in school (reference category = } \\
\text { freshman) }\end{array}$} \\
\hline Sophomore or higher & 0.4634 & 0.3486 & 1.5895 & 0.6015 & 0.3093 & 1.8249 \\
\hline \multicolumn{7}{|l|}{$\begin{array}{l}\text { Parents' monthly income (reference } \\
\text { category }=0-4,999 \text { yuan) }\end{array}$} \\
\hline 5,000 yuan or more & -0.2583 & 0.3260 & 0.7724 & -0.1974 & 0.2855 & 0.8209 \\
\hline \multicolumn{7}{|l|}{$\begin{array}{l}\text { Parents' highest education (reference } \\
\text { category }=\text { high school or lower) }\end{array}$} \\
\hline Associate degree or higher & $-0.7693 *$ & 0.3249 & 0.4633 & -0.4039 & 0.2758 & 0.6677 \\
\hline \multicolumn{7}{|l|}{$\begin{array}{l}\text { Last year total income (reference cat- } \\
\text { egory }=0-4,999 \text { yuan) }\end{array}$} \\
\hline 5,000 yuan or more & -0.5199 & 0.3162 & 0.5946 & $-0.7929 * *$ & 0.2777 & 0.4525 \\
\hline $\begin{array}{l}\text { Full financial dependence on parents } \\
\quad(\text { reference category = no })\end{array}$ & $-0.8174^{*}$ & 0.3180 & 0.4416 & $-0.8133 * *$ & 0.2830 & 0.4434 \\
\hline $\begin{array}{l}\text { Know credit card cash withdraw rate } \\
\quad(\text { reference category }=\text { no })\end{array}$ & 0.5911 & 0.3814 & 1.8060 & $0.8604 *$ & 0.3404 & 2.3641 \\
\hline \multicolumn{7}{|c|}{$\begin{array}{l}\text { Source of financial knowledge (reference } \\
\text { category = parents) }\end{array}$} \\
\hline Internet & -0.1539 & 0.3333 & 0.8574 & 0.0973 & 0.2897 & 1.1022 \\
\hline Other source & -0.0264 & 0.3892 & 0.9739 & 0.2609 & 0.3449 & 1.2981 \\
\hline \multicolumn{7}{|l|}{$\begin{array}{l}\text { Calculated level of financial knowledge } \\
\quad(\text { reference category }=\text { low })\end{array}$} \\
\hline Medium & $-1.3100 * * *$ & 0.3406 & 0.2698 & -0.1727 & 0.3150 & 0.8414 \\
\hline High & $-0.9613 *$ & 0.4302 & 0.3824 & -0.3322 & 0.3969 & 0.7173 \\
\hline Wealth satisfaction $(0-10)$ & -0.0403 & 0.0609 & 0.9605 & -0.0416 & 0.0538 & 0.9593 \\
\hline $\begin{array}{l}\text { I feel that I have strong ability to man } \\
\text { my assets ( } 0 \text { to } 10)\end{array}$ & $0.1187 *$ & 0.0570 & 1.1260 & $0.1656^{* *} *$ & 0.0504 & 1.1801 \\
\hline Chi-square of the likelihood ratio test & $99.0002 * * *$ & & & & & \\
\hline
\end{tabular}

Note. Analysis of Central University of Finance and Economics datasets. Sample size $=499$.

$* p<.05 . * * p<.01 . * * * p<.001$.

\section{Results}

Table 2 reports the results from the multinomial logistic analysis of the respondent students' credit card use behaviors when using "parents pay" as the reference category. As shown in Table 2 , factors negatively associated with the likelihood of paying credit card balances in full each month, aside from having their parents pay, included higher past-year income and full financial dependency on parents. These results rejected the first hypothesis and were inconsistent with results from prior literature (e.g., Lyons, 2004; Mendes-Da-Silva et al., 2012). Those who had incomes over 5,000 yuan in the previous year were $45.3 \%$ more likely to pay their credit card debts in full compared with students with lower incomes. Students who were completely financially dependent on their parents were $44.3 \%$ more likely to make full credit card payments, compared with financially independent students. Factors positively associated with paying credit card balances in full each month, aside from having their parents pay, included having knowledge about credit cards and a strong self-perceived ability to manage assets. Students who knew credit card cash advance rates were 2.4 times more likely to pay credit card balances in full compared with students who reported no such 
knowledge. Students who had higher confidence levels in regards to their asset management skills had increased odds of making full payments by $18.0 \%$.

Factors negatively associated with making at least the minimum payments other than having their parents pay included parents' highest education, full financial dependency, and students' calculated level of financial knowledge. Compared with those whose parents had high school degrees or lower, students whose parents had associate degrees or higher were $46.3 \%$ more likely to pay at least the minimum payment. Students who were fully financially dependent on their parents were $44.2 \%$ more likely to make at least the minimum payment. Students who had a medium or high level of financial knowledge were $27.0 \%$ and $38.2 \%$ more likely to make at least the minimum payment, respectively. In addition, students who had higher confidence in regards to their asset management skills had increased odds of making at least the minimum payments by $12.6 \%$.
Table 3 shows the results from the binary logistic analysis of students' behavior with respect to credit card cash advances. Compared with freshman students, students in higher grades were $50.1 \%$ less likely to take cash advances. Students, whose parents had associate degree or higher, were $46.6 \%$ less likely to take cash advances compared with students whose parents had high school or lower degrees. Students who reported knowledge of the cash withdrawal rates were 5.6 times more likely to withdraw cash from their credit cards compared to those who had no such knowledge. Compared with students who acquired financial knowledge from their parents, those who reported the Internet as their source of financial knowledge were $58.5 \%$ more likely to take out cash advances. Students who reported a high level of financial knowledge were $54.4 \%$ less likely to take cash advances than those who reported a low level of financial knowledge. This result confirmed the second hypothesis. Students who had higher confidence levels in regards to their asset management

\section{TAbLe 3. binary Logistic Analysis of Taking Cash Advance on Credit Cards}

\begin{tabular}{|c|c|c|c|}
\hline Parameter & Coefficient & Standard Error & Odds Ratio \\
\hline Intercept & 2.2234 & 0.4332 & \\
\hline Male (reference category = female) & -0.1872 & 0.2177 & 0.8293 \\
\hline \multicolumn{4}{|l|}{ Year in school (reference category $=$ freshman) } \\
\hline Sophomore or higher & $-0.7023 * *$ & 0.2427 & 0.4954 \\
\hline \multicolumn{4}{|l|}{ Parents' monthly income (reference category $=0-4,999$ yuan) } \\
\hline 5,000 yuan or more & -0.2322 & 0.2414 & 0.7928 \\
\hline \multicolumn{4}{|c|}{ Parents' highest education (reference category $=$ high school or lower) } \\
\hline Associate degree or higher & $-0.6265 * *$ & 0.2382 & 0.5345 \\
\hline \multicolumn{4}{|l|}{ Last year total income (reference category $=0-4,999$ yuan) } \\
\hline 5,000 yuan or more & -0.0533 & 0.2358 & 0.9481 \\
\hline Full financial dependence on parents (reference category = no) & 0.0481 & 0.2273 & 1.0493 \\
\hline Know credit card cash withdraw rate (reference category $=$ no) & $1.7179 * * *$ & 0.3092 & 5.5728 \\
\hline \multicolumn{4}{|l|}{ Source of financial knowledge (reference category = parents) } \\
\hline Internet & $-0.5359 *$ & 0.2505 & 0.5851 \\
\hline Other source & -0.4249 & 0.2762 & 0.6538 \\
\hline \multicolumn{4}{|l|}{ Calculated level of financial knowledge (reference category $=$ low) } \\
\hline Medium & 0.0585 & 0.2462 & 1.0602 \\
\hline High & $-0.7848^{*}$ & 0.3138 & 0.4562 \\
\hline Financial satisfaction $(0-10)$ & -0.0299 & 0.0447 & 0.9705 \\
\hline I feel that I have strong ability to manage my assets ( 0 to 10 ) & $-0.0885^{*}$ & 0.0419 & 0.9153 \\
\hline Chi-square of the likelihood ratio test & $74.1956 * * *$ & & \\
\hline
\end{tabular}

Note. Analysis of Central University of Finance and Economics datasets. Sample size $=499$.

$* p<.05 . * * p<.01 . * * * p<.001$. 
skills showed a decrease in the odds of taking cash advances by $8.5 \%$.

\section{Discussion and Implications}

Using data from 10 universities in China, this study explored factors related to Chinese college students' credit card usage behaviors. Overall, the findings are consistent with previous research. Factors such as previous year's income, financial dependence, and self-reported asset management abilities were associated with respondents' paying behavior. For example, students who reported a stronger ability to manage their assets were more likely to pay off their credit card debt each month. This finding was consistent with that of Xiao et al. (2011), who found that students who feel more confident about managing their finances were more likely to engage in responsible financial behaviors such as paying credit card balances in full and not taking cash advances. Unlike prior research findings, gender was found to be unrelated to credit card paying behavior among Chinese college students.

Financial dependence decreased the probability of paying credit card balances in part or in full each month. Instead, students who were financially dependent on their parents were more likely to let their parents pay their credit card balances. It was interesting to note that students who had higher incomes in the previous year were less likely to pay their monthly credit card debts in full and more likely to have their parents pay. One possible explanation for this is that students with higher incomes received those incomes in the form of allowances from their parents. In the Chinese culture, college students rely on their parents' financial support until they graduate from college and enter the job market (Wang, Kong, Shan, \& Vong, 2010; Liu, 2014). They often do not worry about credit card balances or other financial matters because of the common expectation that their parents will support them.

Palmer, Pinto, and Parente (2001) pointed out that postacquisition parental involvement (financial assistance from parents to their dependents) leads to higher totals of credit card balances. It was interesting but not surprising to find that students whose parents engage in postacquisition involvement engaged in less responsible credit card usage behaviors than those who were independent from their parents. However, it was surprising to find that students who acquired their financial knowledge from parents were more likely to take cash advances than those whose financial knowledge came from the Internet. One possible explanation is that parents told their dependents to take cash advances because they planned on taking care of the fees. This may be prevalent among students who attend a college away from their hometown.

In addition to identifying which students were most likely to engage in undesirable financial behaviors, the findings of this study have clear implications for financial educators and parents. Students who engaged in harmful financial behaviors, such as paying between minimum and full payments and/or taking cash advances as a normal means to access cash, need to understand the consequences of such behaviors. Financial educators and parents should make an effort to not only educate college students about the immediate consequences of such behaviors (e.g., fees and interest charges) but also about the long-term consequences (e.g., a poor credit history, decreased probability of acquiring debt in the future, and increased costs of borrowing). However, financial dependence may prevent college students from identifying with these consequences and weaken the effect of such education. Financial independence may make the education more effective as students can relate to it.

Several factors make it difficult for Chinese college students to achieve complete financial independence from their parents. The main factor is the influence of Chinese traditional family values. Chinese parents tend to invest everything they have in their children's education, which they believe can help their children achieve a relatively high social-economic status. The expectation is that when they are older, their children will take care of them. According to Zhu (2016), in order to repay parents' earlier educational investment, children with a higher education level are more likely to provide greater financial support to their parents. In addition, adult children have the legal obligations to provide financial support and emotional care to older parents. "Supporters of the elderly shall fulfill their obligations of providing for the elderly economically, taking care of them in daily life and comforting them mentally, attending to their special needs. 'Supporters' refer to the children of the elderly and other persons who are under the legal obligation to provide for the elderly" (Law of the People's Republic of China on the Protection of the Rights and Interests of the Elderly, 2015). In this cultural climate, Chinese college students 
are likely to believe that receiving financial support from their parents is normal. According to Liu (2014), only a small proportion of students make money to pay their own tuition. Another factor that negatively affects Chinese college students' financial independence is course arrangements in Chinese universities. Students attend college as cohorts, and their plans of study are largely determined by their academic units, which have inflexible schedules. This lack of flexibility also makes it difficult for college students to find a job that is flexible in time and that also pays enough to support their tuition and living expenses. Because of these factors, it is understandable that Chinese college students have to somewhat rely on their parents for financial support. However, their parents should learn not to encourage their children in college to engage in undesirable credit card behaviors. On the contrary, parents should encourage their children in college to engage in responsible financial behaviors during their college years and prepare them for a financially responsible life after they graduate from college.

The findings of this study also provide implications for policymakers and educators. Because of the prevalence of unemployment and full financial dependence on parents among Chinese college students, policymakers should consider whether it is appropriate for these college students to use credit cards. Due to some of the malpractice behaviors of credit card salespersons at banks, including opening a credit card account without the consent of the student, the regulator virtually stopped the banks from marketing credit cards to college students in 2009. However, in recent years, with the rapid onset of effects from the Internet and smartphones, more institutions and platforms have been using the Internet to market credit card products to college students, resulting in some students' over-indebtedness and bad credit records. Appropriate use of a credit card is necessary to address regarding issues related to credit. Therefore, it might be a good idea for policymakers to allow banks to issue small-limit credit cards, for example, with a limit of 500 yuan, helping the students build a good credit history before they start using higher-limit credit cards. Students who engage in harmful financial behaviors, such as not making minimum payments and/or taking cash advances as a normal option to obtain cash, need to be educated with respect to credit card usage. Therefore, it is necessary to offer financial planning courses on college campuses nationwide. One limitation of the current study is that the number of credit cards that the students owned was not included. The information was collected in the survey; we excluded this variable because of the small sample size regarding students who own multiple credit cards. Future study should consider whether ownership and usage of multiple credit cards are significantly related to undesirable credit paying behaviors. Future research is necessary to explore factors associated with financial literacy among college students in China and evaluate the effectiveness of financial educational programs. Future studies should consider whether the number of credit cards owned is related to undesirable credit paying behaviors.

\section{References}

Akben-Selcuk, E. (2015). Factors influencing college students' financial behaviors in Turkey: Evidence from a national survey. International Journal of Economics and Finance, 7(6), 87-94. http://dx.doi.org/10.5539/ ijef.v7n6p87

Bowen, C. F. (2002). Financial knowledge of teens and their parents. Journal of Financial Counseling and Planning, 13(2), 93-102.

China Real News. (2014). Chinese credit cards top 400 million Chatham: Newstex. Retrieved from http://proxy. mul.missouri.edu/login?url=http://search.proquest. com/docview/1553034123? accountid=14576

China Real News. (2015). Chinese five biggest banks' credit card issuances account for $64.5 \%$ of total issued by listed banks Chatham: Newstex. Retrieved from http:// proxy.mul.missouri.edu/login?url=http://search.proquest.com/docview/1727776564?accountid=14576

Fernandes, D., Lynch, J. G., \& Netemeyer, R. G. (2014). Financial literacy, financial education, and downstream financial behaviors. Management Science, 60(8), 18611883. http://dx.doi.org/10.1287/mnsc.2013.1849 Jassim, A. A., \& Taylor, J. C. (2010). College students' credit card usage and debt. Competition Forum, 8(1), 101-110.

Joo, S., Grable, J. E., \& Bagwell, D. C. (2003). Credit card attitudes and behaviors of college students. College Student Journal, 37(3), 405-420.

Law of the People's Republic of China on the Protection of the Rights and Interests of the Elderly. (2015). 2 Standing Committee of the National People's Congress. 14.

Li, W., Wang, R., \& Xu, X. (2014). The effects of college students' attitude change on the using of credit card. 
Proceedings of the 2014 International Conference on Global Economy, Commerce, and Service Science (GECSS-14). Atlantis Press.

Liu, H. C. (2014). An analysis of consumer behavior of college students born in the 1990s in China. Canadian Social Science, 10(6), 186-189.

Ludlum, M., Tilker, K., Ritter, D., Cowart, T., Xu, W., \& Smith, B. C. (2012). Financial literacy and credit cards: A multi-campus survey. International Journal of Business and Social Science, 3(7), 25-33.

Lyons, A. C. (2004). A profile of financially at-risk college students. Journal of Consumer Affairs, 38(1), 56-80. http://dx.doi.org/10.1111/j.1745-6606.2004.tb00465.x

Measures for the Supervision and Administration of the Credit Card Business of Commercial Banks. (2011). 2 China banking regulatory commission. 44-45.

Mendes-Da-Silva, W., Nakamura, W. T., \& Moraes, D. Cde. (2012). Credit card risk behavior on college campuses: Evidence from Brazil. BAR - Brazilian Administration Review, 9(3), 351-373. http://dx.doi.org/10.1590/ S1807-76922012000300007

Norvilitis, J. M., \& MacLean, M. G. (2010). The role of parents in college students' financial behaviors and attitudes. Journal of Economic Psychology, 31(1), 55-63. http://dx.doi.org/10.1016/j.joep.2009.10.003

Norvilitis, J. M., \& Mao, Y. (2013). Attitudes towards credit and finances among college students in China and the United States. International Journal of Psychology, 48(3), 389-398. http://dx.doi.org/10.1080/00207594. 2011.645486

Palmer, T. S., Pinto, M. B., \& Parente, D. H. (2001). College students' credit card debt and the role of parental involvement: Implications for public policy. Journal of Public Policy \& Marketing, 20(1), 105-113. http://dx. doi.org/10.1509/jppm.20.1.105.17293

People.cn. (2016). Chinese college students need to correct bad spending habits of over consumption. Retrieved from http://edu.people.com.cn/n1/2016/0922/c105328731888.html

Pinto, M. B., Parente, D. H., \& Mansfield, P. M. (2005). Information learned from socialization agents: Its relationship to credit card use. Family and Consumer Sciences Research Journal, 33(4), 357-367. http://dx.doi. org/10.1177/1077727X04274113

Robb, C. A. (2011). Financial knowledge and credit card behavior of college students. Journal of Family and
Economic Issues, 32(4), 690-698. http://dx.doi.org/10. 1007/s10834-011-9259-y

Robb, C. A., \& Sharpe, D. L. (2009). Effect of personal financial knowledge on college students' credit card behavior. Journal of Financial Counseling and Planning, 20(1), 25-43.

Sallie Mae. (2013). How America Pays for College 2013. Sallie Mae's National Study of College Students and Parents. Conducted by Ipsos Public Affairs. Retrieved from http://news.salliemae.com/files/doc_library/file/ HowAmericaPaysforCollege2014FNL.pdf

Sallie Mae. (2016). Majoring in money: How American college students manage their finances. Conducted by ipsos public affairs. Retrieved from https://news.salliemae. com/sites/salliemae.newshq.businesswire.com/files/ doc_library/file/SallieMae_MajoringinMoney_2016.pdf Sharpe, D. L., Yao, R., \& Liao, L. (2012). Correlates of credit card adoption in urban China. Journal of Family and Economic Issues, 33(2), 156-166. http://dx.doi. org/10.1007/s10834-012-9309-0

Staten, M., \& Barron, J. M. (2002). College student credit card usage (Credit Research Center Working Paper No. 65). Retrieved from http://faculty.msb.edu/prog/ CRC/pdf/WP65.pdf

Statista. (2016). Annual growth of the total number of credit cards in China from 2007 to 2014. Retrieved from http://www.statista.com/statistics/450052/china-creditcard-number-growth/

Tan, D. L. (2003). Oklahoma college student credit card study. Norman, OK: University of Oklahoma, Center for Student Affairs Research.

Wang, H., Kong, M., Shan, W., \& Vong, S. K. (2010). The effects of doing part-time jobs on college student academic performance and social life in a Chinese society. Journal of Education and Work, 23(1), 79-94. http:// dx.doi.org/10.1080/13639080903418402

Wang, L., Lu, W., \& Malhotra, N. K. (2011). Demographics, attitude, personality and credit card features correlate with credit card debt: A view from China. Journal of Economic Psychology, 32(1), 179-193. http://dx. doi.org/10.1016/j.joep.2010.11.006

Worthington, S. (2003). The Chinese payment card market: An exploratory study. International Journal of Bank Marketing, 21(6/7), 324-334. http://dx.doi.org/10. $1108 / 02652320310498474$

Worthington, S., Stewart, D., \& Lu, X. (2007). The adoption and usage of credit cards by urban-affluent consumers in 
China. International Journal of Bank Marketing, 25(4), 238-252. http://dx.doi.org/10.1108/02652320710754024

Worthington, S., Thompson, F. M., \& Stewart, D. B. (2011).

Credit cards in a Chinese cultural context-The young, affluent Chinese as early adopters. Journal of Retailing and Consumer Services, 18(6), 534-541. http://dx.doi. org/10.1016/j.jretconser.2011.07.003

Xiao, J. J., Ahn, S. Y., Serido, J., \& Shim, S. (2014). Earlier financial literacy and later financial behaviour of college students. International Journal of Consumer Studies, 38(6), 593-601. http://dx.doi.org/10.1111/ijcs.12122
Xiao, J. J., Tang, C., Serido, J., \& Shim, S. (2011). Antecedents and consequences of risky credit behavior among college students: Application and extension of the theory of planned behavior. Journal of Public Policy and Marketing, 30(2), 239-245. http://dx.doi. org/10.1509/jppm.30.2.239

Zhu, H. (2016). Adult children's characteristics and intergenerational financial transfers in urban China. Chinese Journal of Sociology, 2(1), 75-94. http://dx.doi. org/10.1177/2057150X15624085 